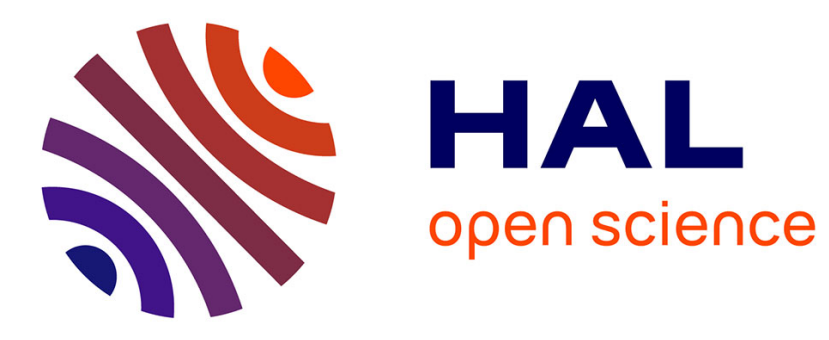

\title{
Characterization of TseB: A new actor in cell wall elongation in Bacillus subtilis
}

\author{
Jordan Delisle, Baptiste Cordier, Stéphane Audebert, Matthieu Pophillat, \\ Caroline Cluzel, Leon Espinosa, Christophe Grangeasse, Anne Galinier, \\ Thierry Doan
}

\section{To cite this version:}

Jordan Delisle, Baptiste Cordier, Stéphane Audebert, Matthieu Pophillat, Caroline Cluzel, et al.. Characterization of TseB: A new actor in cell wall elongation in Bacillus subtilis. Molecular Microbiology, 2021, 10.1111/mmi.14798 . hal-03330256

\section{HAL Id: hal-03330256 https://hal.science/hal-03330256}

Submitted on 29 Sep 2021

HAL is a multi-disciplinary open access archive for the deposit and dissemination of scientific research documents, whether they are published or not. The documents may come from teaching and research institutions in France or abroad, or from public or private research centers.
L'archive ouverte pluridisciplinaire HAL, est destinée au dépôt et à la diffusion de documents scientifiques de niveau recherche, publiés ou non, émanant des établissements d'enseignement et de recherche français ou étrangers, des laboratoires publics ou privés. 


\section{Characterization of TseB, a new actor in cell wall elongation in Bacillus subtilis}

Jordan Delisle ${ }^{1}$, Baptiste Cordier ${ }^{1}$, Stéphane Audebert ${ }^{2}$, Matthieu Pophillat ${ }^{2}$, Caroline Cluzel $^{3}$, Leon Espinosa ${ }^{1}$, Christophe Grangeasse ${ }^{4}$, Anne Galinier ${ }^{1 *}$ and Thierry Doan ${ }^{1 *}$

${ }^{1}$ Laboratoire de Chimie Bactérienne, UMR 7283, CNRS/Aix-Marseille Univ, Institut de Microbiologie de la Méditerranée, 31, Chemin Joseph Aiguier, Marseille, France

${ }^{2}$ Aix-Marseille Univ, INSERM, CNRS, Institut Paoli-Calmettes, CRCM, Marseille Protéomique, Marseille, France

${ }^{3}$ Laboratoire de Biologie Tissulaire et Ingénierie Thérapeutique, UMR 5305, CNRS/Université Lyon I, Lyon, France

${ }^{4}$ Molecular Microbiology and Structural Biochemistry, UMR 5086, CNRS/Université Lyon I, Lyon, France

Running Title: TseB, a new member of the elongasome in Bacillus subtilis

Key Words: peptidoglycan, cell wall, penicillin-binding-protein, PepSY, Bacillus subtilis

* To whom correspondence should be addressed:

Anne Galinier : galinier@imm.cnrs.fr

Thierry Doan : $\underline{\text { tdoan@imm.cnrs.fr }}$ 


\section{SUMMARY}

Penicillin-binding proteins (PBPs) are crucial enzymes of peptidoglycan assembly and targets of ß-lactam antibiotics. However, little is known about their regulation. Recently, membrane proteins were shown to regulate the bifunctional transpeptidases/ glycosyltransferases aPBPs in some bacteria. However, up to now, regulators of monofunctional transpeptidases bPBPs have yet to be revealed. Here, we propose that TseB could be such a PBP regulator. This membrane protein was previously found to suppress tetracycline sensitivity of a Bacillus subtilis strain deleted for ezrA, a gene encoding a regulator of septation ring formation. Here we show that TseB is required for B. subtilis normal cell shape, tseB mutant cells being shorter and wider than wild-type cells. We observed that TseB interacts with PBP2A, a monofunctional transpeptidase. While TseB is not required for PBP2A activity, stability and localization, we show that the overproduction of PBP2A is deleterious in the absence of TseB. In addition, we showed that TseB is necessary not only for efficient cell wall elongation during exponential phase but also during spore outgrowth, as it was also observed for PBP2A. Altogether our results suggest that TseB is a new member of the elongasome that regulates PBP2A function during cell elongation and spore germination. 


\section{INTRODUCTION}

The cell wall forms a sturdy shell that protects bacteria from osmotic bursting, defines and maintains their specific shape. It is mainly composed of peptidoglycan (PG), a continuous meshed polymer made of long glycan chains crosslinked by peptide side chains. Importantly, constant remodeling of the PG exoskeleton is required for bacterial growth and division (Egan et al., 2020, Sassine et al., 2020). This process relies on the accurate balance between the degradation of existing bonds by PG hydrolases and the incorporation of new material by PG synthases, including Penicillin-Binding Proteins (PBPs) (van Heijenoort \& van Heijenoort, 1980, Scheffers \& Pinho, 2005) and Shape, Elongation, Division and Sporulation (SEDS) proteins (Meeske et al., 2016, Sjodt et al., 2020). Hence, therapeutic interests have yielded massive focus into the determinants of PG synthesis (Alter et al., 2018, Shalaby et al., 2020, Hugonnet et al., 2016). The pathways implicated in the synthesis of the PG, i.e. synthesis of precursor lipid II in the cytoplasm and PG extracellular polymerization, have been extensively studied. In this process, lipid II is first made by a series of enzymatic reactions in the cytoplasm (Mengin-Lecreulx et al., 1982). Then, it is translocated across the membrane by a membrane flippase and is incorporated into nascent PG by glycosyltransferase (GTase) and transpeptidase (TPase) activities of PBPs (Scheffers \& Pinho, 2005). Among these PBPs, the bifunctional PBPs of class A (aPBPs) possess both GTase and TPase activities whereas the monofunctional PBPs of class B (bPBPs) have only a TPase activity. The glycan chain is polymerized by SEDS proteins and aPBPs and then attached to the existing sacculus by the TPase activity of both aPBPs and bPBPs (Sjodt et al., 2020).

Recent research on cell wall synthesis has appreciably advanced our understanding of how these enzymes are regulated to achieve dynamic PG remodeling as cells elongate and divide (Egan et al., 2020, Egan et al., 2015); it is now evident that PBP activities are also diversely regulated by extracellular factors. Protein-protein interactions between known components have been described to promote either dimerization or proper localization of specific PBPs. For example, in Escherichia coli, the FtsN division protein likely enhances the activity of the aPBP, PBP1B, by promoting its dimerization (Müller et al., 2007). A significant step forward was made with the identification of two outer membrane lipoproteins, LpoA and LpoB that are critical activators of two aPBPs, PBP1A and PBP1B 
in E. coli (Paradis-Bleau et al., 2010, Typas et al., 2011, Typas et al., 2010). More recently, it was shown that the lipoprotein LpoP is essential for PBP1B function in Pseudomonas aeruginosa (Greene et al., 2018). However, these lipoproteins are only conserved in Gammaproteobacteria and Enterobacteria. Nevertheless, these major findings support the idea that diverse extracellular partners may regulate universally conserved PBPs in bacteria. Following this discovery, a few partners of cell wall enzymes have been described. Notably, potential regulators of aPBPs were reported in the Gram-positive coccoid bacteria Streptococcus pneumoniae and Staphylococcus aureus (Stamsås et al., 2018, Fenton et al., 2016, Fenton et al., 2018). For example, it was proposed that CozE and $\mathrm{CozEb}$ direct cell wall elongation by regulating PBP1A localization and stimulates its activity (Fenton et al., 2016, Stamsås et al., 2020). However, up to now, no potential regulator of bPBPs has been reported.

In the rod-shaped Gram-positive bacterium Bacillus subtilis, 16 genes encode for PBPs and the products of 11 of them have been analyzed biochemically (Foster \& Popham, 2001). Single and multiple deletions of these genes suggest a redundancy in function for both classes A and B of PBPs (Sassine et al., 2017). For example, the co-essential PBP2A and PBPH transpeptidases (bPBPs) are TPases usually associated with lateral cell wall elongation. They appear to be fully redundant during vegetative growth. Indeed, single deletion of either $p b p A$ (encoding PBP2A) or $p b p H$ had no detectable effect on cell shape but they display synthetic lethality (Wei et al., 2003). Despite extensive studies of this model bacterium and the presence of CozE homologues, no regulator of PBPs has been reported in B. subtilis.

Here we propose that the TseB protein (previously Y $\mathrm{pmB}$ ) could be such a partner of the bPBP PBP2A in B. subtilis. A deletion of tseB was previously shown to cause a shorter cell phenotype and to rescue the tetracycline hypersensitivity of an ezrA mutant (Gamba et al., 2015). In addition, a $t s e B$ mutant strain has an increased resistance to moenomycin, an antibiotic that inhibits the transglycosylase activity of class A PBPs (Zhao et al., 2018). However, it remains unclear why a deletion of $e z r A$ renders $B$. subtilis cells hypersensitive for tetracycline and why a deletion of tseB renders $B$. subtilis cells hyper resistant for moenomycin. The tseB gene belongs to an operon composed of three genes: $y p m A$, tseB and $\operatorname{asp} B$; no obvious function has been described for ypmA but aspB encodes a putative 
aspartate transaminase required for the biosynthesis of aspartate; a $\Delta a s p B$ mutant strain growing in rich medium with limited Asp ceases growth and lyses due to depletion of mDAP, an essential intermediate for PG synthesis (Zhao et al., 2018). Here we found that B. subtilis tseB mutant cells were misshapen, being shorter and wider than wild-type cells. Interestingly, we observed that TseB interacts with PBP2A. Our data suggest that TseB, even if it is not essential for PBP2A activity, may regulate PBP2A function.

\section{RESULTS AND DISCUSSION}

\section{The absence of TseB affects cell shape in B. subtilis}

To identify new proteins involved in morphogenesis, we screened a B. subtilis mutant library (Kobayashi et al., 2003) at the single-cell level using fluorescence microscopy to detect mutants with abnormal cell shape. One of the first hit we obtained was the mutant deleted for the $t s e B$ gene. Indeed, we observed that the shape of $t s e B$ mutant cells was distinct from that of wild-type cells grown in LB rich medium to exponential phase (Fig. 1). Quantitative analysis of cell dimensions showed that in average $\Delta t s e B$ deletion mutant cells were $16 \%$ shorter and $14 \%$ wider than wild-type cells (Fig. 1A). Heat maps generated with more than 1000 cells further highlighted the difference between $\Delta t s e B$ and wild-type populations (Fig. 1B). To exclude a downstream polar effect on $\operatorname{aspB}$, we constructed a complementation strain in which we introduced an ectopic IPTG-inducible copy of $t s e B$. In the presence of inducer, normal cell shape was restored (Fig. 1A and 1C). TseB is thus necessary for normal cell shape in B. subtilis.

TseB is predicted to be a single-pass membrane protein of 161 amino acids with a very short $\mathrm{N}$-terminal intracellular domain and a large $\mathrm{C}$-terminal extracellular region (Fig. 2A). Searches based on Pfam (multiple sequence alignments and hidden Markov models) indicated that this extracellular region (PDP entry: 2GU3) contains two PepSY domains

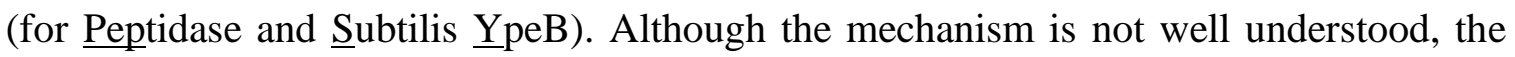
PepSY domain is thought to regulate extracellular peptidases and glycosylases and to inhibit peptidase activity prior to the release of the enzyme in the environment (Yeats et $a l ., 2004)$. In addition, it can be found in many bacterial and archeal proteins that do not display obvious extracellular peptidase activity. This domain was first characterized in the YpeB protein, which is necessary for the stability, the localization and the activity of SleB, 
a lytic glycosylase necessary for spore cortex PG degradation during germination in $B$. subtilis (Sayer \& Popham, 2019, Bernhards et al., 2015). The interaction between SleB and YpeB protects both proteins from proteolysis and inhibits SleB glycosylase activity during sporulation. Once spore outgrowth is favorable, YpeB is degraded by extracellular proteases, presumably to release SleB lytic activity on cortex PG (Sayer \& Popham, 2019, Bernhards et al., 2015, Bernhards \& Popham, 2014, Korza \& Setlow, 2013). Another case is the SspA lipoprotein of Streptomyces coelicolor, which possesses two PepSY domains and is necessary for proper septum positioning (Tzanis et al., 2014). Interestingly, it was suggested that SspA might interact with or regulate PBPs or other enzymes involved in cell wall remodeling.

\section{TseB interacts with PBP2A}

It was previously observed that a GFP-TseB fusion showed clear membrane localization that is enriched at cell division sites in some cells and almost absent from matured septa (Gamba et al., 2015). We therefore generated a TseB-sfGFP fusion that is expressed ectopically and we observed that our TseB-sfGFP fusion presented similar membrane localization, enriched at septa, suggesting that sfGFP, fused to the predicted extracytoplasmic domain of $\mathrm{TseB}$ does not interfere with localization (Fig. S1). We therefore used the TseB-sfGFP fusion to search for TseB partners by coimmunoprecipitation with detergent-solubilized membrane proteins and a resin with coupled anti-GFP antibodies. In contact with the resin, TseB-sfGFP was well depleted from the solubilized membrane protein fraction (Fig. 2B). Proteins present in the eluates were then identified by liquid chromatography coupled to mass spectrometry analysis. Among proteins present in the TseB-sfGFP eluate, we can find proteins involved in cell elongation like two PBPs, PBP2A and PBP1A, and Mbl, a MreB paralog (Table S1). However, the two proteins that were exclusively eluted and predominantly scored were TseB and PBP2A (Fig. 2C and Table S1).

PBP2A is a bPBP that belongs to the elongasome (Errington \& Wu, 2017); it is required for cell wall synthesis during cell elongation and works together with the SEDS protein RodA for lateral cell wall synthesis and determination of cell diameter (Cho et al., 2016, Dion et al., 2019). In B. subtilis, the elongasome is composed of two distinct cell wall synthetic systems, the Rod complex and the aPBPs. Cell shape and in particular cell width 
is determined by the opposing actions of these two systems (Dion et al., 2019). The Rod complex (composed of RodA, the bPBP PBP2a and/or PbpH, MreC, MreD, RodZ, and filaments of MreB) reduces diameter, while the aPBPs increase it. Increased Rod complex activity correlates with an increased density of directional MreB filaments and a greater fraction of directional PBP2a enzymes (Dion et al., 2019). In addition, overexpression of $\operatorname{rodA}$ increases cell diameter, but only when $\mathrm{PBP} 2 \mathrm{~A}$ synthesis is also sufficiently high (Dion et al., 2019). Since the deletion of $t s e B$ induces an increase in cell diameter and a reduction of cell size, it is tempting to consider that TseB is part of the elongasome complex and regulates the activity of $\mathrm{PBP} 2 \mathrm{~A}$. It is therefore possible that TseB interacts directly and specifically with PBP2A or that this interaction is indirect in the elongasome and TseB could coordinate the proper functioning of this protein complex to permit an optimal cell elongation. However, the predominance of TseB and PBP2A in the coimmunoprecipitation eluate hinted towards a specific interaction between these two proteins. To test this hypothesis, we used a pull-down assay (Fig. 3). We overproduced the soluble extracellular domain of PBP2A fused to glutathione S-transferase (GST) in E. coli and immobilized the fusion protein on a glutathione resin (Fig. 3A). The extracellular domain of TseB was fused to a His-tag and overproduced in E. coli as well. The crude lysate was incubated with immobilized GST-PBP2A, with the E. coli proteins in the crude lysate serving as competitors. After extensive washing, GST-PBP2A was released from the resin. Proteins were then analyzed by SDS-PAGE and Coomassie staining and immunoblot for TseB. His-TseB bound to the extracellular domain of PBP2A and both domains were found in the eluate (Fig. 3A), supporting the idea that PBP2A and TseB extracellular domains interact. We also did several controls (Fig. 3B, 3C and 3D). We detected no interaction between the extracellular domain of $\mathrm{TseB}$ and the extracellular domain of $\mathrm{YjcN}$, another membrane protein we are studying, fused to GST (Fig. 3B) and between GSTPBP2A and the intracellular domain of YqgP fused to a His-tag (Began et al., 2020) (Fig. 3C).

\section{TseB is not necessary for PBP2A activity, stability and localization}

Since TseB interacts with PBP2A and is required for the optimal cell elongation, we propose that it is a component of the elongasome. It was previously observed that a deletion of $p b p A$ (encoding $\mathrm{PBP} 2 \mathrm{~A}$ ) has no detectable effect on cell shape during exponential 
growth (Murray et al., 1997, Wei et al., 2003). Here we showed that a tseB deletion results in shorter and wider cells in comparison to wild-type cells. This suggests that even if TseB directly regulates $\mathrm{PBP} 2 \mathrm{~A}$ activity, it is likely not an $\mathrm{ON}-\mathrm{OFF}$ activator of $\mathrm{PBP} 2 \mathrm{~A}$. It may also regulate other proteins involved in cell elongation that could be missed in the coimmunoprecipitation experiment, such as integral membrane proteins that are difficult to solubilize or identify by mass spectrometry, like RodA.

Since we observed an interaction between TseB and PBP2A, we decided to focus on the relationship between these two proteins and thus to combine deletions of tseB and $p b p H$. This last gene encodes PBPH, the second bPBP of B. subtilis required for cell elongation whose deletion is synthetic lethal with $p b p A$ deletion. Thus, if TseB is necessary for PBP2A activity, combined deletions of $t s e B$ and $p b p H$ would be synthetic lethal. Yet, a $\Delta t s e B$ $\Delta p b p H$ double mutant was easily generated (Fig. 4A). We also easily generated a $\Delta t s e B$ $\triangle p b p A$ double mutant. These two double mutants have the same characteristic as the $\Delta t s e B$ single mutant, i.e. shorter and wider than wild-type cells and $p b p A$ or $p b p H$ simple mutant cells (see Fig. 4B). This observation indicates that TseB is not essential for PBP2A and PBPH activities.

We next wondered whether TseB could spatially influence the localization of PBP2A. We therefore compared the localization of a functional GFP-PBP2A fusion in wild-type and a $\Delta t s e B$ mutant. PBP2A was previously observed to be localized to discrete foci or patches along all membranes in wild-type cells (Scheffers et al., 2004). Here we observed a similar localization of GFP-PBP2A and we did not detect any apparent perturbation of this pattern in $\Delta t s e B$ cells suggesting that TseB does not affect PBP2A localization (Fig. 5A). Then, we checked if TseB could influence the stability of PBP2A, as described for YpeB/SleB in B. subtilis (Bernhards et al., 2015). We thus tested whether the absence of TseB had an impact on the amount and stability of PBP2A by western blot using anti-PBP2A antibodies that we generated. As shown in Fig. 5B, the absence of TseB has no apparent effect on PBP2A stability.

\section{TseB is required upon PBP2A overexpression}

The lack of TseB induces an increase in the cell diameter and a reduction of cell size; this suggests a positive role for TseB on the Rod complex and thus on PBP2A activity. To further analyze if and potentially how TseB influences PBP2A function, we tested if the 
overproduction of PBP2A can compensate the absence of TseB. For that, we build an ectopic copy of $p b p A$ under the control of a strong inducible IPTG-inducible promoter in a wild-type and in a $\Delta t s e B$ background. As a control, we checked that PBP2A is efficiently overproduced in the presence of increasing IPTG concentrations in the presence or absence of TseB (Fig. 6B). We observed that PBP2A overproduction had little effects on morphology in a wild-type background. However, in the absence of TseB, PBP2A overproduction was not able to restore normal shape (Fig. 6A). This observation indicates that higher amounts of PBP2A cannot offset the absence of TseB. We conclude that either PBP2A activity is not activated by $\mathrm{TseB}$ or the role of TseB is not limited to PBP2A stimulation.

However and surprisingly, we observed that cell dimensions were compromised in a dosedependent manner in a $\Delta t s e B$ background (Fig. 6C). Notably, strong PBP2A overexpression (1 mM IPTG) generated $12 \%$ of curvy shapes (n>500) (Fig. 6A, blue carets) in the absence of $t s e B$ (Fig. 6A, orange carets). This result suggested that the cell wall was largely perturbed when PBP2A was overproduced in the absence of TseB. Moreover, closer inspection by electron microscopy showed that the overproduction of PBP2A in the absence of TseB had a strong impact on the cell wall layer. The thickness of the PG layer was somewhat heterogeneous and globally augmented, most strikingly at the cell poles (Fig. 6D and Fig. S2). As a control, we performed a similar experiment with PBPH. We were not able to raise antibodies against PBPH to monitor its overproduction. However at least, we know that our $p b p H$ inducible construct is functional because both $p b p A$ and $p b p H$ can be deleted upon $p b p H$ ectopic induction, even at very low concentrations of inducers (data not shown). Then, we observed that ectopic $p b p H$ induction had no significant effect on cell shape either in the presence or in the absence of TseB (Fig. S2 and S3). Together, our data show that TseB specifically allows higher amounts of PBP2A to be tolerated suggesting that the function of PBP2A depends on its partner TseB. In other words, this observation suggests that either TseB may have a role in limiting PBP2A activity and might act negatively on PBP2A or permits that PBP2A functions correctly in the elongasome.

In any case, TseB seems necessary for PBP2A to function correctly. But could the putative stimulatory effect of TseB on PBP2A (a tseB mutant has a larger diameter than wild-type) 
and the putative inhibitory effect of TseB (PBB2A overproduction is toxic in the absence of TseB) be reconciled? At least two hypotheses can be considered. Maybe, TseB acts differentially on PBP2A depending the physiological context. For example, it could have a non-essential positive effect on PBP2A when they are part of the elongasome complex but inhibit PBP2A activity when PBP2A is outside of the elongasome, such as when PBP2A is overproduced. Alternatively, in addition to PBP2A, TseB may have other targets in the elongasome, and regulates other proteins involved in cell elongation (like RodA or PBP1A...). In this hypothesis, TseB could help to the good functioning of PBP2A and maybe of other proteins of the elongasome complex. This could explain also the fact that during exponential phase, $t s e B$ mutant cells are shorter and wider than $p b p A$ mutant cells.

\section{TseB is required for spore germination}

We reasoned that if the absence of TseB leads to PBP2A malfunction, the role of TseB would be particularly important during spore outgrowth when PBP2A has a more pronounced function. Indeed, spores lacking PBP2A were significantly delayed in spore outgrowth and exhibited distorted morphologies (Murray et al., 1998, Murray et al., 1997). Murray and colleagues further proposed that compensatory transpeptidase activity (of PBPH presumably) is either absent or insufficient during spore outgrowth. Thus, if TseB is required for PBP2A proper activity, a $t s e B$ mutant should also be altered for spore outgrowth kinetic. To test this prediction, we analyzed germination kinetics by microscopy and measuring the optical density of a wild-type strain, a $\Delta t s e B$ mutant, a strain harboring an ectopic IPTG inducible copy of $t s e B$ in a $\Delta t s e B$ mutant background, a $\triangle p b p A$ mutant, and a strain harboring an ectopic IPTG inducible copy of $p b p A$ in a $\triangle p b p A$ mutant background (Fig. 7). While the initiation of spore germination was similar for all strains and whatever their genetic background (Fig. 7B), the tseB mutant spores subsequently exhibited a significant delay in outgrowth as compared to wild-type spores (Fig. 7A). This delay is comparable to that observed for $p b p A$ mutant spores. Indeed, for the WT strain, after $120 \mathrm{~min}$, the germinated cells began to elongate and to divide; in contrast, the $p b p A$ and the $t s e B$ mutant spores failed to elongate (Fig. 7B). After $4 \mathrm{~h}$ in culture, many of the outgrowing $p b p A$ and $t s e B$ spores began to elongate and to divide although cells are swelled for the $p b p A$ mutant, as previously observed (Murray et al., 1997). We conclude that, TseB is required to efficiently elongate into cylindrical cells during spore germination, 
supporting the idea that $\mathrm{TseB}$ is required for the critical activity of PBP2A during spore outgrowth.

In conclusion, we showed that TseB has an important role in cell wall elongation, not only in growing cells but also in spore outgrowth. Our results suggest that TseB probably regulates PBP2A activity and may do so through a direct interaction. This is the first time that a putative regulator of a monofunctional class B PBP is reported. This is also the first time that a putative regulator of a PBP is reported in the bacterium $B$. subtilis. Since tseB is conserved in many Gram-positive bacteria, it will be interesting to analyze the role of its homologs in other bacteria, in particular in cocci where the elongation process is different from the one existing in rod-shaped bacteria.

\section{EXPERIMENTAL PROCEDURES}

\section{Plasmid and strain construction}

All B. subtilis strains were derived from the prototrophic strain $168 \operatorname{trpC}+($ Nicolas et al., 2012). The strains, plasmids and primers used in this study are listed in Tables 1, 2 and 3 respectively. pJM51 [His-PBP2 $\mathrm{A}^{\mathrm{ECD}}$ ] was generated in a two-way ligation with a BamHIXhoI PCR product encoding PBP2A extracellular domain (oligonucleotide primers oJM9 and oJM81 and wild- type genomic DNA as template) and pET28a cut with BamHI and XhoI. pJM52 [amyE::Phyperspank-tseB (spec)] was generated in a two-way ligation with a HindIII- NheI PCR product encoding tseB (oligonucleotide primers oTM194 and oTM195 and wild- type genomic DNA as template) and pDR111 (a kind gift from David Rudner)

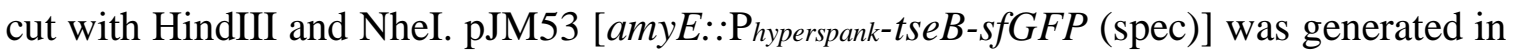
a two-way ligation with a HindIII-XhoI PCR product encoding tse $B$ (oligonucleotide primers oTM194 and oTM196 and wild-type genomic DNA as template) and pBM21

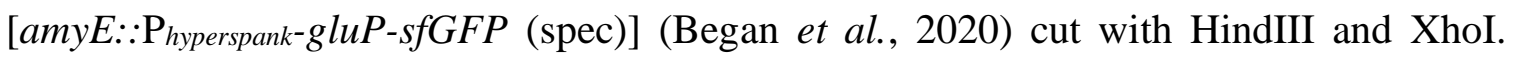
pTM52 [His-TseB ${ }^{\mathrm{ECD}}$ ] was generated in a two-way ligation with a NheI-XhoI PCR product encoding a C-terminal extracellular fragment of TseB (134 amino acids, oligonucleotide primers oTM225 and oTM226 and wild-type genomic DNA as template) and pET28a cut

with NheI and XhoI. pJM1 [GST-PPB2A ${ }^{\mathrm{ECD}}$ ] was generated in a two-way ligation with a BamHI-EcoRI PCR product encoding PBP2A extracellular domain (oligonucleotide primers oJM9 and oJM10 and wild-type genomic DNA as template) and pGEX-4-T1 
(Amersham) cut with BamHI and EcoRI. pTM112 [GST-YjcN ${ }^{\mathrm{ECD}}$ ] was generated in a twoway ligation with a BamHI-EcoRI PCR product encoding YjcN extracellular domain (oligonucleotide primers oTM375 and oTM376 and wild-type genomic DNA as template) and pGEX-4-T1 (GE Life Sciences) cut with BamHI and EcoRI. pTM68 [amyE::PhyperspankpbpA (spec)] was built in a two-way ligation with a HindIII-NheI PCR product encoding PBP2A (oligonucleotide primers oJM65 and oJM58 and wild-type genomic DNA as

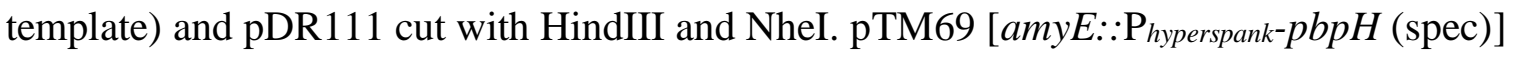
was built in a two-way ligation with a HindIII-NheI PCR product encoding PBPH (oligonucleotide primers oJM68 and oJM69 and wild-type genomic DNA as template) and pDR111 cut with HindIII and NheI.

\section{Protein purification and antibody production}

The soluble domains of PBP2A and TseB (His-tagged fusions) were expressed in E. coli BL21 DE3 pLysS. Cells were grown in $\mathrm{LB}$ at $37^{\circ} \mathrm{C}$ to an $\mathrm{OD}_{600}$ of 0.6 , then shifted to $16^{\circ} \mathrm{C}$ and induced by addition of IPTG to $1 \mathrm{mM}$ overnight.

For PBP2A and TseB with a 6His- tag, cells were harvested by centrifugation and resuspended in 1/50th volume Buffer I (50 mM Tris- $\mathrm{HCl} \mathrm{pH} \mathrm{8,} 300 \mathrm{mM} \mathrm{NaCl}, 5 \mathrm{mM} 2$ Mercaptoethanol, $10 \mathrm{mM}$ imidazole) and flash-frozen. A crude extract was prepared by freeze-thawing the cells followed by 2 passes in a French press. A soluble fraction was made by 100,000X g spin and was loaded on a $1 \mathrm{~mL} \mathrm{Ni2+-NTA}$ agarose (Qiagen) column equilibrated with Buffer I. Bound protein was washed with Buffer I containing $20 \mathrm{mM}$ Imidazole, and eluted in Buffer I containing $120 \mathrm{mM}$ Imidazole and $10 \%$ glycerol.

For GST fusions, cells were harvested by centrifugation and resuspended in 1/50th volume Buffer II (20 mM Tris-HCl pH 8, 200 mM NaCl, 1 mM EDTA, 5 mM 2-Mercaptoethanol, $1 \mathrm{mM}$ PMSF) and flash frozen. A crude extract was prepared by freeze-thawing the cells followed 2 passes in a French press. A soluble fraction was made by 100,000X g spin and was loaded on a $1 \mathrm{~mL}$ glutathione-agarose column equilibrated with Buffer II. Bound protein was washed successively with Buffer II containing $200 \mathrm{mM}, 1 \mathrm{M} \mathrm{NaCl}$ and 200 $\mathrm{mM} \mathrm{NaCl}$. Proteins were then eluted in Buffer II containing $10 \mathrm{mM}$ glutathione and $10 \%$ Glycerol.

Purified proteins were used to generate polyclonal antibodies (Agro-Bio, France) and for in vitro interaction assays. 


\section{Co-immunoprecipitation from detergent solubilized membrane fractions}

All procedures were performed as described (Doan et al., 2009). For crude membrane preparation, BTM291 (amyE::Phyprspank-tseB-sfgfp (spec)) or the wild-type strain were grown in $\mathrm{LB}$ at $37^{\circ} \mathrm{C}$. At $\mathrm{OD} 0.6,50 \mathrm{~mL}$ were harvested for membrane preparation. Membrane proteins were solubilized by the addition of the nonionic detergent DDM ( $\mathrm{n}$ dodecyl- $\beta$-d-maltopyranoside, Sigma) to a final concentration of $0.5 \%$. The soluble fraction (the load) was mixed with $25 \mu 1$ anti-GFP antibody resin (Chromotek) and rotated for $4 \mathrm{~h}$ at $4^{\circ} \mathrm{C}$. The resin was pelleted at $3 \mathrm{Krpm}$ and the supernatant (the flow through) was removed. After washes, immunoprecipitated proteins were eluted by the addition of 85.5 $\mu 1$ of Sodium Dodecyl Sulfate sample buffer and heated for 15 minutes at $50^{\circ} \mathrm{C}$. The eluted material (the IP) was transferred to a fresh tube and 2-Mercaptoethanol was added to a final concentration 400 of $10 \%$. The load, flow through and IP were analyzed by immunoblot.

\section{Protein mass spectrometry analysis}

Mass spectrometry analyses were performed as described previously (Cartier-Michaud et al., 2017). Raw files generated from mass spectrometry analysis were processed with Proteome Discoverer 1.4 (Thermo Fisher Scientific), searching data via in-house Mascot server (version 2.4.1; Matrix Science Inc., London, UK) against the B. subtilis database (4300 references) of the Swissprot database (version 2020.04). For the database search, the following settings were used: a maximum of one miscleavage, oxidation as a variable modification of methionine, carbamidomethylation as a fixed modification of cysteine and trypsin was set as the enzyme. A peptide mass tolerance of $6 \mathrm{ppm}$ and a fragment mass tolerance of $0.8 \mathrm{Da}$ was used for search analysis. Only peptides with high stringency identity Mascot score (false discovery rate $(\mathrm{FDR})<1 \%$ ) were used for protein identification.

\section{Protein interaction assay (pull-down)}

Purified GST-PBP2A (extracellular domain) or GST-YjcN (extracellular domain) was bound to Glutathione-agarose resin (Thermofisher) and washed with 5 column volumes of Buffer III (20 mM Tris-HCl pH 8, 100 mM NaCl, 1 mM EDTA, 5 mM 2-Mercaptoethanol, $1 \mathrm{mM}$ PMSF). The soluble lysate containing His-tagged TseB (extracellular domain) or YqgP also named GluP (N-terminal domain) (Began et al., 2020) was incubated for $2 \mathrm{~h}$ with the resin containing GST fusions. The resin was then washed with 3 column volumes

of Buffer III. Bound proteins were eluted with SDS sample buffer. Eluted proteins were 
separated by SDS-PAGE and visualized with Coomassie blue or by western blot.

\section{Immunoblot analysis}

Proteins were separated by SDS-PAGE on $12.5 \%$ polyacrylamide gels, electroblotted onto Immobilon-P membranes (Millipore) and blocked in $5 \%$ nonfat milk in phosphatebuffered saline (PBS)-0.5\% Tween-20. The blocked membranes were probed with antiTseB $(1: 10,000)$, anti-PBP2A $(1: 10,000)$ or affinity purified anti-GFP $(1: 10,000)$. The primary antibodies were diluted into $1 \mathrm{X}$ PBS, 0.05\% Tween-20, 3\% BSA. Primary antibodies were detected using horseradish peroxidase-conjugated goat, anti-rabbit $G$ (Dako) and the Western Lightning Pro kit (PerkinElmer).

\section{Spore germination}

$10 \mathrm{ml}$ samples of cultures grown during $72 \mathrm{H}$ in DSM medium were pelleted in a microcentrifuge, and washed with $1 \mathrm{ml}$ of PBS. Spores were heat shocked at $80^{\circ} \mathrm{C}$ for 30 min then washed 3 times $1 \mathrm{ml}$ of $\mathrm{H}_{2} 0$. The spores germinated at $37^{\circ} \mathrm{C}$ in $10 \mathrm{ml}$ of $\mathrm{LB}$ medium with $5 \mathrm{mM}$ L-alanine. The initial optical density at $600 \mathrm{~nm}$ of each culture was approximately 0.1 . Spore germination was monitored by phase contrast microscopy and by measuring the optical density.

\section{Phase contrast and fluorescent microscopy and data analysis}

Microscopy was performed with a Zeiss AxioImager M2 equipped with an OrcaR2 digital camera (Hamamatsu) as previously described (Rudner \& Losick, 2002, Foulquier et al., 2011). For fluorescence microscopy, exposure times were typically $500 \mathrm{~ms}$ for GFP. The membrane dye FM1-43 (Thermofischer) was used at a final concentration of $0.01 \mathrm{mM}$ and exposure times were typically $200 \mathrm{~ms}$. Images were adjusted and cropped using the Zen software (Carl Zeiss). Cell length and diameter were measured using the ObjectJ plugin (https://sils.fnwi.uva.nl/bcb/objectj) (Vischer et al., 2015) for ImageJ (http://imagej.nih.gov/ij/). Selected images are representative of experiments made in triplicate. For any strain and condition, over 750 cells were analyzed (usually around 1000 cells). Statistical dataset analysis was performed using the $\mathrm{R}$ software environment (https://www.r-project.org/).

\section{Electron Microscopy}

B. subtilis cells were grown in LB in the presence of $100 \mu \mathrm{M}$ IPTG and were collected during exponential growth phase $\left(\mathrm{OD}_{600} \sim 0.5\right)$. Sample preparation was performed as 
previously described (Fleurie et al., 2012) Cells were examined with a Philips CM120 transmission electron microscope equipped with a Gatan Orius SC200 CCD camera.

\section{REFERENCES}

Alter, S.J., Sanfilippo, C.M., Asbell, P.A., and DeCory, H.H. (2018) Antibiotic Resistance Among Pediatric-Sourced Ocular Pathogens: 8-year Findings from the ARMOR Surveillance Study. Pediatr Infect Dis J.

Began, J., Cordier, B., Březinová, J., Delisle, J., Hexnerová, R., Srb, P., ... and Strisovsky, K. (2020) Rhomboid intramembrane protease YqgP licenses bacterial membrane protein quality control as adaptor of FtsH AAA protease. EMBO J 39: e102935.

Bernhards, C.B., Chen, Y., Toutkoushian, H., and Popham, D.L. (2015) HtrC is involved in proteolysis of YpeB during germination of Bacillus anthracis and Bacillus subtilis spores. J Bacteriol 197: 326-336.

Bernhards, C.B., and Popham, D.L. (2014) Role of YpeB in cortex hydrolysis during germination of Bacillus anthracis spores. J Bacteriol 196: 3399-3409.

Cartier-Michaud, A., Bailly, A.L., Betzi, S., Shi, X., Lissitzky, J.C., Zarubica, A., ... and Aurrand-Lions, M. (2017) Genetic, structural, and chemical insights into the dual function of GRASP55 in germ cell Golgi remodeling and JAM-C polarized localization during spermatogenesis. PLoS Genet 13: e1006803.

Cho, H., Wivagg, C.N., Kapoor, M., Barry, Z., Rohs, P.D.A., Suh, H.,... and Bernhardt, T.G. (2016) Bacterial cell wall biogenesis is mediated by SEDS and PBP polymerase families functioning semi-autonomously. Nat Microbiol 1: 16172.

Dion, M.F., Kapoor, M., Sun, Y., Wilson, S., Ryan, J., Vigouroux, A., ... and Garner, E.C. (2019) Bacillus subtilis cell diameter is determined by the opposing actions of two distinct cell wall synthetic systems. Nat Microbiol 4: 1294-1305.

Doan, T., Morlot, C., Meisner, J., Serrano, M., Henriques, A.O., Moran, C.P., and Rudner, D.Z. (2009) Novel secretion apparatus maintains spore integrity and developmental gene expression in Bacillus subtilis. PLoS Genet 5: e1000566. 
Egan, A.J., Biboy, J., van't Veer, I., Breukink, E., and Vollmer, W. (2015) Activities and regulation of peptidoglycan synthases. Philos Trans R Soc Lond B Biol Sci 370.

Egan, A.J.F., Errington, J., and Vollmer, W. (2020) Regulation of peptidoglycan synthesis and remodelling. Nat Rev Microbiol 18: 446-460.

Errington, J., and Wu, L.J. (2017) Cell Cycle Machinery in Bacillus subtilis. Subcell Biochem 84: 67-101.

Fenton, A.K., El Mortaji, L., Lau, D.T., Rudner, D.Z., and Bernhardt, T.G. (2016) CozE is a member of the MreCD complex that directs cell elongation in Streptococcus pneumoniae. Nat Microbiol 2: 16237.

Fenton, A.K., Manuse, S., Flores-Kim, J., Garcia, P.S., Mercy, C., Grangeasse, C., ... and Rudner, D.Z. (2018) Phosphorylation-dependent activation of the cell wall synthase PBP2a in. Proc Natl Acad Sci U S A 115: 2812-2817.

Fleurie, A., Cluzel, C., Guiral, S., Freton, C., Galisson, F., Zanella-Cleon, I., ... and Grangeasse, C. (2012) Mutational dissection of the S/T-kinase StkP reveals crucial roles in cell division of Streptococcus pneumoniae. Mol Microbiol 83: 746-758.

Foster, S.J., and Popham, D.L., (2001) Structure and synthesis of cell wall, spore cortex, teichoic acids, S - layers, and capsules . In: Bacillus subtilis and its Relatives: from Genes to Cells. Sonenshein, L. , Losick, R., and Hoch, J.A., pp. 21 - 41.

Foulquier, E., Pompeo, F., Bernadac, A., Espinosa, L., and Galinier, A. (2011) The YvcK protein is required for morphogenesis via localization of PBP1 under gluconeogenic growth conditions in Bacillus subtilis. Mol Microbiol 80: 309318.

Gamba, P., Rietkötter, E., Daniel, R.A., and Hamoen, L.W. (2015) Tetracycline hypersensitivity of an ezrA mutant links GalE and TseB (YpmB) to cell division. Front Microbiol 6: 346.

Greene, N.G., Fumeaux, C., and Bernhardt, T.G. (2018) Conserved mechanism of cellwall synthase regulation revealed by the identification of a new PBP activator in. Proc Natl Acad Sci U S A 115: 3150-3155. 
Hugonnet, J.E., Mengin-Lecreulx, D., Monton, A., den Blaauwen, T., Carbonnelle, E., Veckerlé, C., ... and Arthur, M. (2016) Factors essential for L,D-transpeptidasemediated peptidoglycan cross-linking and $\beta$-lactam resistance in. Elife $\mathbf{5}$.

Kobayashi, K., Ehrlich, S.D., Albertini, A., Amati, G., Andersen, K.K., Arnaud, M., ... and Ogasawara, N. (2003) Essential Bacillus subtilis genes. Proc Natl Acad Sci U S A 100: 4678-4683.

Korza, G., and Setlow, P. (2013) Topology and accessibility of germination proteins in the Bacillus subtilis spore inner membrane. J Bacteriol 195: 1484-1491.

Meeske, A.J., Riley, E.P., Robins, W.P., Uehara, T., Mekalanos, J.J., Kahne, D., ... and Rudner, D.Z. (2016) SEDS proteins are a widespread family of bacterial cell wall polymerases. Nature 537: 634-638.

Mengin-Lecreulx, D., Flouret, B., and van Heijenoort, J. (1982) Cytoplasmic steps of peptidoglycan synthesis in Escherichia coli. J Bacteriol 151: 1109-1117.

Murray, T., Popham, D.L., Pearson, C.B., Hand, A.R., and Setlow, P. (1998) Analysis of outgrowth of Bacillus subtilis spores lacking penicillin-binding protein 2a. J Bacteriol 180: 6493-6502.

Murray, T., Popham, D.L., and Setlow, P. (1997) Identification and characterization of pbpA encoding Bacillus subtilis penicillin-binding protein 2A.J Bacteriol 179: 3021-3029.

Müller, P., Ewers, C., Bertsche, U., Anstett, M., Kallis, T., Breukink, E., ... and Vollmer, W. (2007) The essential cell division protein FtsN interacts with the murein (peptidoglycan) synthase PBP1B in Escherichia coli. J Biol Chem 282: 3639436402.

Nicolas, P., Mäder, U., Dervyn, E., Rochat, T., Leduc, A., Pigeonneau, N., ... and Noirot, P. (2012) Condition-dependent transcriptome reveals high-level regulatory architecture in Bacillus subtilis. Science 335: 1103-1106.

Paradis-Bleau, C., Markovski, M., Uehara, T., Lupoli, T.J., Walker, S., Kahne, D.E., and Bernhardt, T.G. (2010) Lipoprotein cofactors located in the outer membrane activate bacterial cell wall polymerases. Cell 143: 1110-1120. 
Rudner, D.Z., and Losick, R. (2002) A sporulation membrane protein tethers the prosigmaK processing enzyme to its inhibitor and dictates its subcellular localization. Genes Dev 16: 1007-1018.

Sassine, J., Sousa, J., Lalk, M., Daniel, R.A., and Vollmer, W. (2020) Cell morphology maintenance in Bacillus subtilis through balanced peptidoglycan synthesis and hydrolysis. Sci Rep 10: 17910.

Sassine, J., Xu, M., Sidiq, K.R., Emmins, R., Errington, J., and Daniel, R.A. (2017) Functional redundancy of division specific penicillin-binding proteins in Bacillus subtilis. Mol Microbiol 106: 304-318.

Sayer, C.V., and Popham, D.L. (2019) YpeB dimerization may be required to stabilize SleB for effective germination of Bacillus anthracis spores. BMC Microbiol 19: 169.

Scheffers, D.J., Jones, L.J., and Errington, J. (2004) Several distinct localization patterns for penicillin-binding proteins in Bacillus subtilis. Mol Microbiol 51: 749-764.

Scheffers, D.J., and Pinho, M.G. (2005) Bacterial cell wall synthesis: new insights from localization studies. Microbiol Mol Biol Rev 69: 585-607.

Shalaby, M.W., Dokla, E.M.E., Serya, R.A.T., and Abouzid, K.A.M. (2020) Penicillin binding protein 2a: An overview and a medicinal chemistry perspective. Eur J Med Chem 199: 112312.

Sjodt, M., Rohs, P.D.A., Gilman, M.S.A., Erlandson, S.C., Zheng, S., Green, A.G., ... and Kruse, A.C. (2020) Structural coordination of polymerization and crosslinking by a SEDS-bPBP peptidoglycan synthase complex. Nat Microbiol 5: 813-820.

Stamsås, G.A., Myrbråten, I.S., Straume, D., Salehian, Z., Veening, J.W., Håvarstein, L.S., and Kjos, M. (2018) CozEa and CozEb play overlapping and essential roles in controlling cell division in Staphylococcus aureus. Mol Microbiol 109: 615-632.

Stamsås, G.A., Restelli, M., Ducret, A., Freton, C., Garcia, P.S., Håvarstein, L.S., ... and Kjos, M. (2020) A CozE Homolog Contributes to Cell Size Homeostasis of Streptococcus pneumoniae. mBio 11.

Typas, A., Banzhaf, M., Gross, C.A., and Vollmer, W. (2011) From the regulation of peptidoglycan synthesis to bacterial growth and morphology. Nat Rev Microbiol 10: 123-136. 
Typas, A., Banzhaf, M., van den Berg van Saparoea, B., Verheul, J., Biboy, J., Nichols, R.J., ... and Vollmer, W. (2010) Regulation of peptidoglycan synthesis by outermembrane proteins. Cell 143: 1097-1109.

Tzanis, A., Dalton, K.A., Hesketh, A., den Hengst, C.D., Buttner, M.J., Thibessard, A., and Kelemen, G.H. (2014) A sporulation-specific, sigF-dependent protein, SspA, affects septum positioning in Streptomyces coelicolor. Mol Microbiol 91: 363380.

van Heijenoort, Y., and van Heijenoort, J. (1980) Biosynthesis of the peptidoglycan of Escherichia coli K-12: properties of the in vitro polymerization by transglycosylation. FEBS Lett 110: 241-244.

Vischer, N.O., Verheul, J., Postma, M., van den Berg van Saparoea, B., Galli, E., Natale, P., ... and den Blaauwen, T. (2015) Cell age dependent concentration of Escherichia coli divisome proteins analyzed with ImageJ and ObjectJ. Front Microbiol 6: 586.

Wei, Y., Havasy, T., McPherson, D.C., and Popham, D.L. (2003) Rod shape determination by the Bacillus subtilis class B penicillin-binding proteins encoded by $p b p A$ and $p b p H$. J Bacteriol 185: 4717-4726.

Yeats, C., Rawlings, N.D., and Bateman, A. (2004) The PepSY domain: a regulator of peptidase activity in the microbial environment? Trends Biochem Sci 29: 169172.

Zhao, H., Roistacher, D.M., and Helmann, J.D. (2018) Aspartate deficiency limits peptidoglycan synthesis and sensitizes cells to antibiotics targeting cell wall synthesis in Bacillus subtilis. Mol Microbiol 109: 826-844.

\section{Acknowledgements}

We would like to thank D. Rudner for support and comments. We kindly thank D-J. Scheffers for strains. We thank D. Byrne, E. Foulquier, C. Morlot and A. Turbé-Doan for help with protein biochemistry and interaction studies. Proteomic analyses were done using the mass spectrometry facility of Marseille Proteomics (marseille-proteomique.univamu.fr) supported by IBISA (Infrastructures Biologie Santé et Agronomie), Plateforme Technologique Aix-Marseille, the Cancéropôle PACA, the Provence-Alpes-Côte d'Azur 
Région, the Institut Paoli-Calmettes and the Centre de Recherche en Cancérologie de Marseille, Fonds Européen de Developpement Regional and Plan Cancer. This work was supported by the CNRS, Aix-Marseille University, a Marie-Curie International Reintegration Grant (PIRG08-GA-2010 619 276750) to TD and an ANR Grant (ANR-19CE15-0011) to AG and CG. JD was supported by fellowships from AMU and the Fondation pour la Recherche Médicale (FRM, FDT20160435133).

\section{Author contributions}

JD, AG and TD conceived the experiments. JD was the major experimental contributor. JD, BC, SA, MP, CC, AG and TD contributed to experiments and data analysis. LE participated to data analysis. CG, AG and TD edited the manuscript. AG and TD wrote the original draft.

\section{Competing interests}

The authors declare no competing interests. 


\section{FIGURES}

(a)

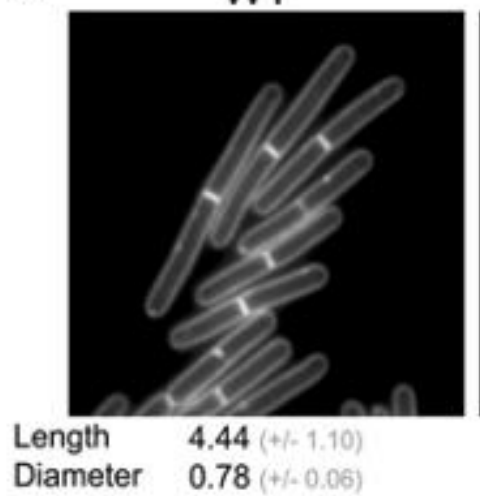

(b)

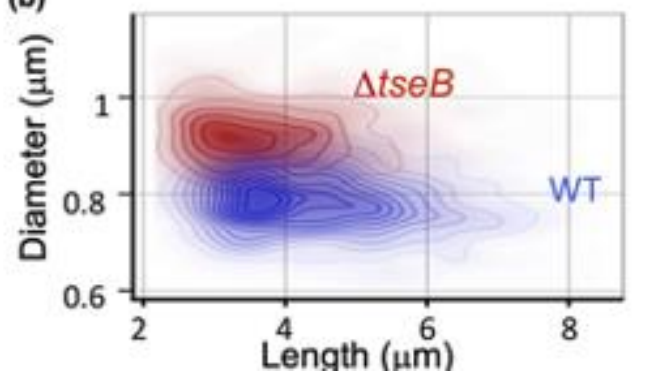

$\Delta t s e B$

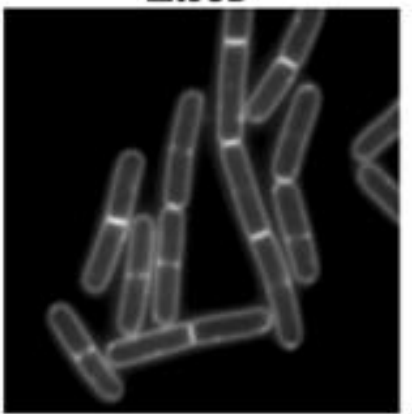

$3.66(+1-0.81)$

$0.92(+/-0.07)$

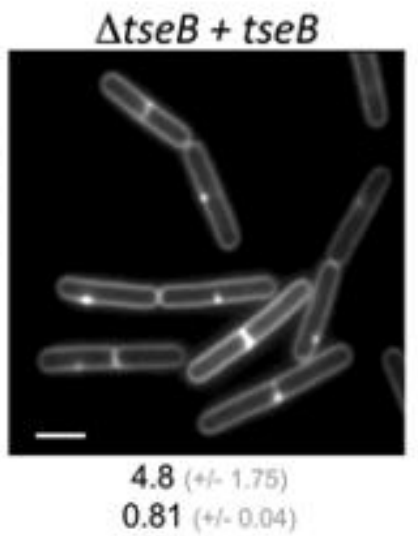

(c)

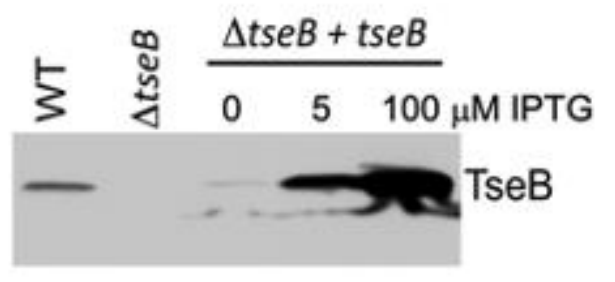

Figure 1: Analysis of length and diameter of $\Delta t s e B$ mutant cells.

A- Cells were grown in LB in the presence of $100 \mu \mathrm{M}$ IPTG and shape was monitored by fluorescence microscopy during growth phase (OD600 0.6) in wild-type (WT), a $\Delta t s e B$ mutant (BJM19) and a strain harboring an ectopic IPTG inducible copy of $t s e B$ in a $\Delta t s e B$ mutant background (BJM21). For each strain, average cell length and diameter is indicated ( $\mathrm{n}>200)$. Membranes were visualized using the dye FM1-43. Scale bar, $2 \mu \mathrm{m}$.

B- Heat map distribution of cell length and diameter (in $\mu \mathrm{m}$ ) between a wild-type strain population (blue) and the $\Delta t s e B$ mutant population (red) $(\mathrm{n}>1000)$.

C- The levels of TseB were monitored by immunoblot of whole cell lysates from the same strains using anti-TseB antibodies. TseB was induced with 5 or $100 \mu \mathrm{M}$ IPTG. 
(a)

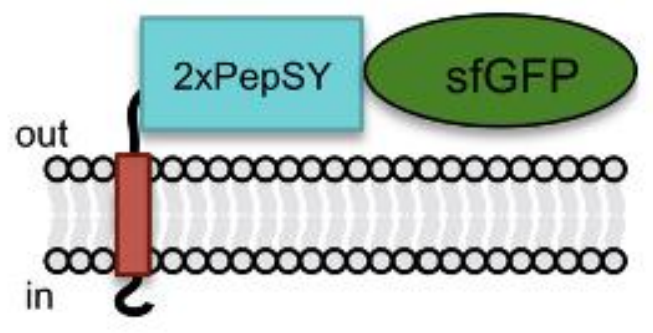

(b)

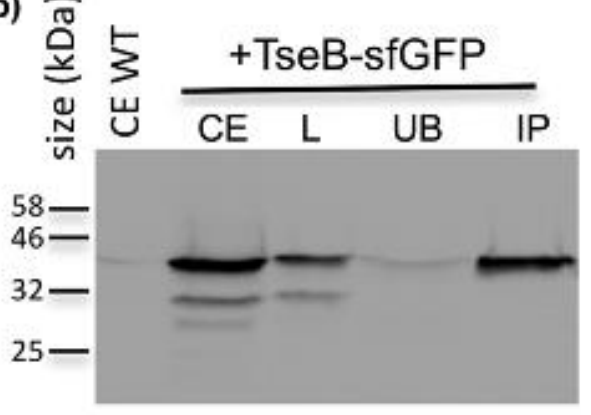

(c)

\begin{tabular}{|c|c|c|c|c|c|c|}
\hline Protein & Gene name & Top3 Area & $\begin{array}{c}\text { Sequence } \\
\text { coverage }\end{array}$ & $\begin{array}{c}\text { Mascot } \\
\text { score }\end{array}$ & $\begin{array}{c}\text { Number of } \\
\text { identified } \\
\text { peptides }\end{array}$ & $\begin{array}{c}\text { Number of } \\
\text { unique } \\
\text { peptides }\end{array}$ \\
\hline TseB & $t s e B$ & $4.710^{8}$ & 60 & 2568 & 80 & 13 \\
\hline PBP2A & $p b p A$ & $1.610^{8}$ & 53 & 5831 & 153 & 39 \\
\hline
\end{tabular}

Figure 2: Characterization of TseB partners.

A- Drawing of the TseB-sfGFP used for co-immunoprecipitation and expressed in strain BTM291.

B- Western blot control of co-immunoprecipitation fractions using anti-GFP antibodies.

Franctions analyzed are the cell extract after cell lysis (CE), the detergent-solubilized membrane fraction prior to immunoprecipitation (L), the supernatant after immunoprecipitation or unbound fraction (UB), and the immunoprecipitates (IP) are shown. Protein size marker is shown on the left $(\mathrm{kDa})$.

C- LC-MS/MS using LTQ-Velos-Orbitrap mass spectrometry analysis of proteins coimmunoprecipitated with TseB-sfGFP. TOP3 Area, protein sequence coverage (in \%), Mascot score, number of peptide-spectrum matches (identified peptides) and number of unique identified peptides are indicated for the proteins TseB and PBP2A. The entire analysis is presented in Table S1. 

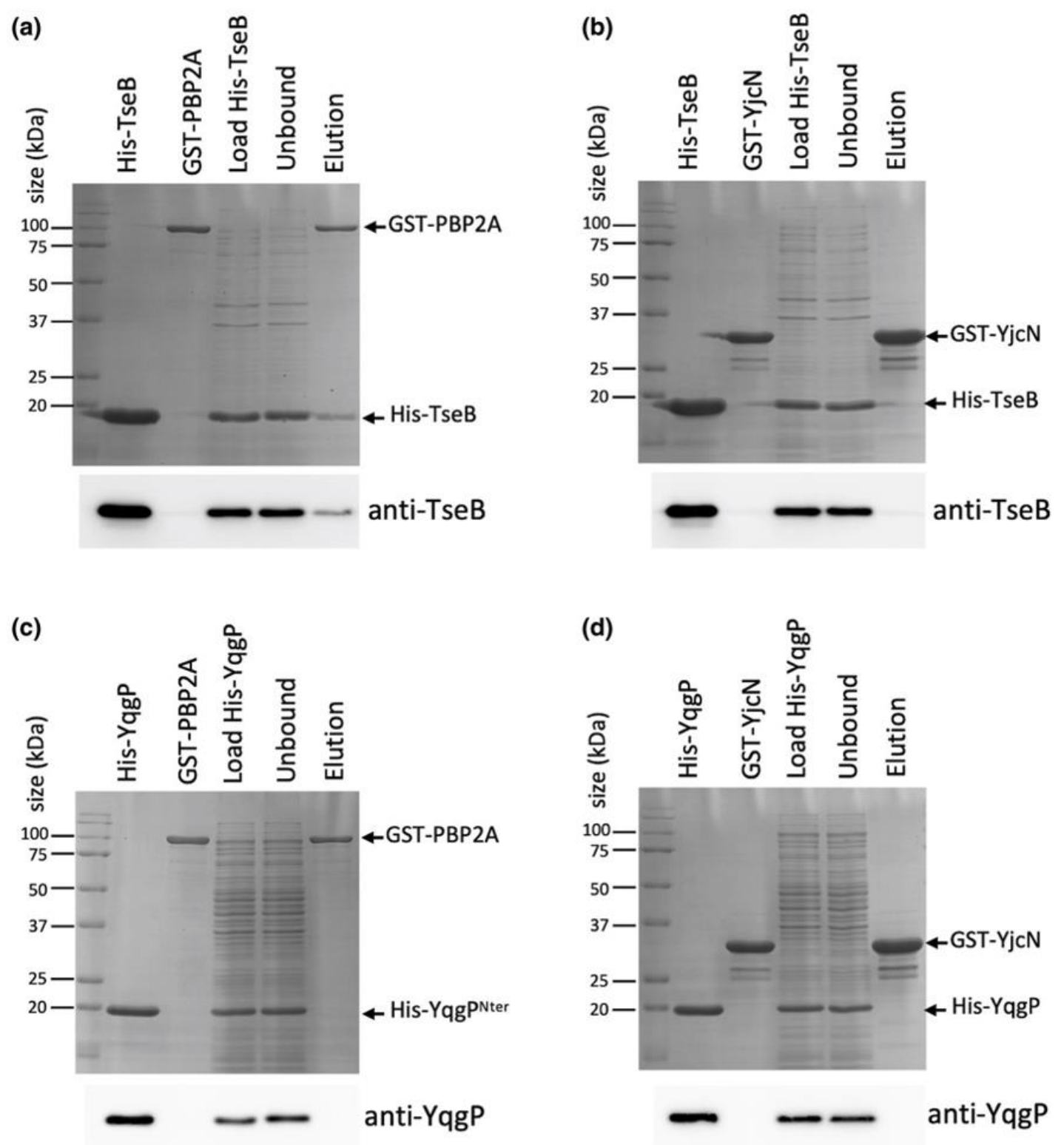

Figure 3: Coomassie stained SDS-polyacrylamide gels of immobilized-protein interaction assays (pull down).

A- GST-PBP2A and His-TseB (extracellular domains). Purified proteins were loaded in the two first lanes for reference. An E. coli lysate containing His-TseB was mixed with a glutathione resin containing GST-PBP2A. Load, Unbound fraction (UB) and elution are shown. Protein size marker is shown on the left $(\mathrm{kDa})$. The presence of His-TseB and HisYqgP in the different fractions was analyzed by western blot with anti-TseB and anti-YqgP antibodies, respectively. 
B- Same experiment with GST-YjcN and His-TseB.

C- Same experiment with GST-PBP2A and His-YqgP.

D- Same experiment with GST-YjcN and His-YqgP. 
(a)
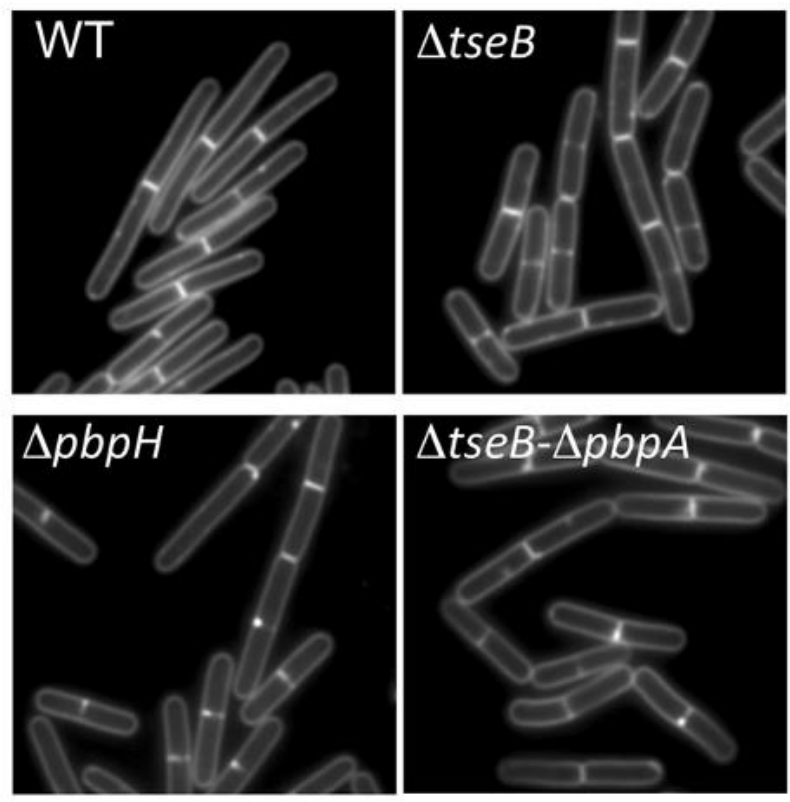

$\Delta t s e B-\triangle p b p A$

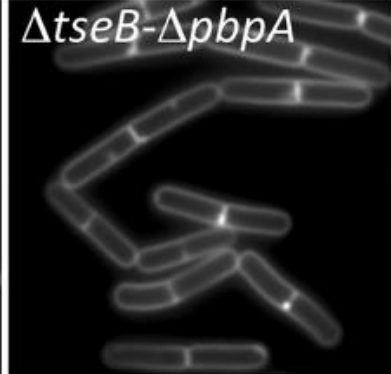

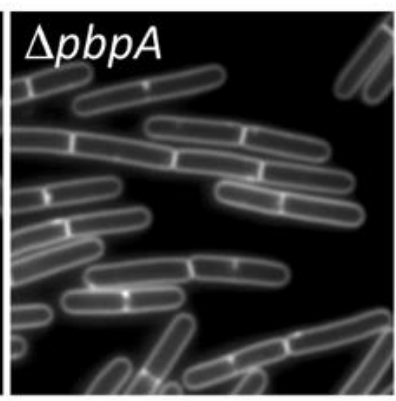

$\Delta t s e B-\Delta p b p H$

(b)
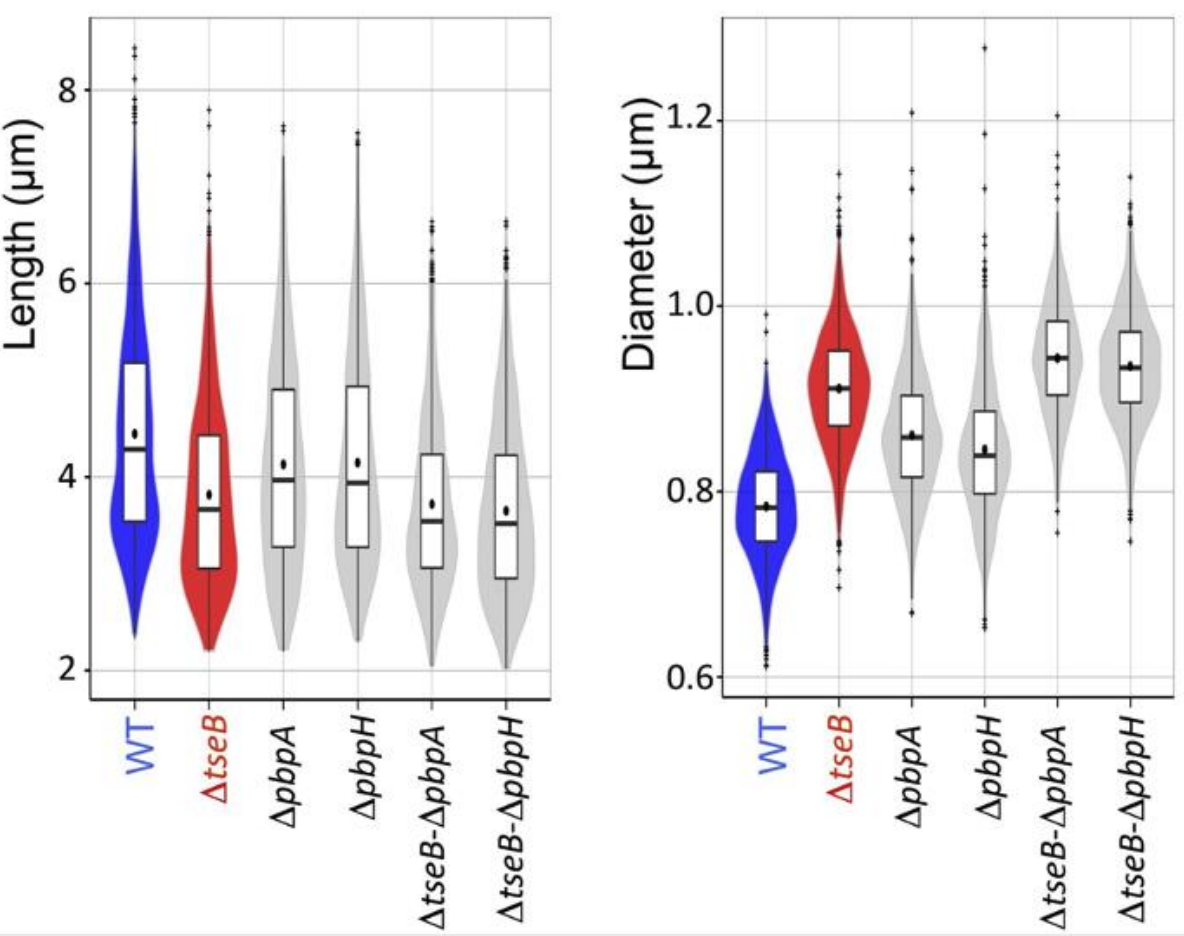

Figure 4: Analysis of morphological variations in the absence of TseB, PBP2A and

\section{PBPH.}

A- Morphological variations were analyzed for cells from wild-type (WT), $\Delta t s e B$ mutant (BJM19), $\triangle p b p A$ mutant (BTM380), $\Delta p b p H$ mutant (BTM382), $\Delta$ tseB- $\Delta p b p A$ double mutant (BTM402), and $\Delta t s e B-\Delta p b p H$ double mutant (BJM36) strains. Bacteria were 
grown in LB and cell shape was monitored by fluorescence microscopy during exponential growth phase $\left(\mathrm{OD}_{600} \sim 0.6\right)$. Cell membranes were visualized using the dye FM1-43. Scale bar, $2 \mu \mathrm{m}$.

B- Single-cell analysis of cell length and diameter (in $\mu \mathrm{m}$ ). Violin plots showing cell length and diameter (in $\mu \mathrm{m})$ quantification in the same strains $(n>750)$. Student's t-test on all groups (versus WT) generated p values below 0.001 . 

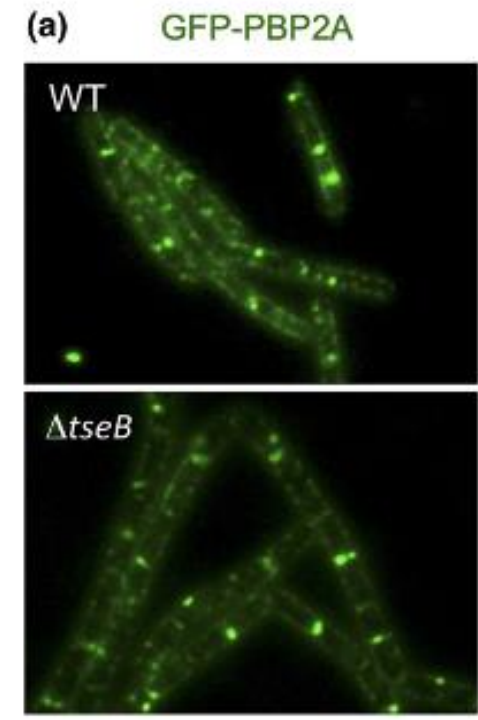

Merge

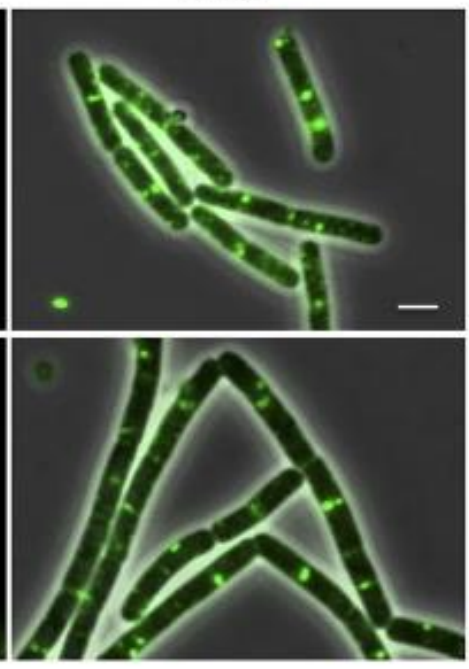

(b)

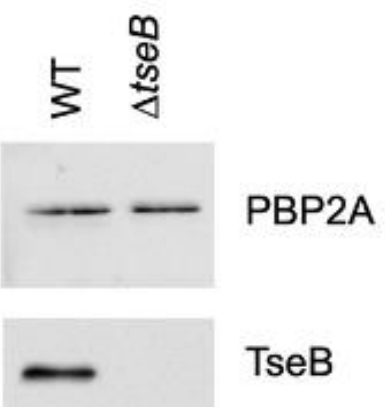

Figure 5: Analysis of GFP-PBP2A localization and stability in the absence of TseB.

A- GFP-PBP2A localization was monitored in the presence (BJM61) or absence TseB (BJM80). Cells were grown in LB and localization was monitored by fluorescence microscopy during exponential growth phase (OD600 0.6). The synthesis of GFP-PBP2A was induced with $0.1 \%$ xylose. Scale bar, $2 \mu \mathrm{m}$

B- WT and $\Delta t s e B$ mutant (BJM19) strains were grown in LB. The stability of PBP2A was monitored by western blot using anti-PBP2A antibodies. The presence of TseB was checked using anti-TseB antibodies. 
(a)
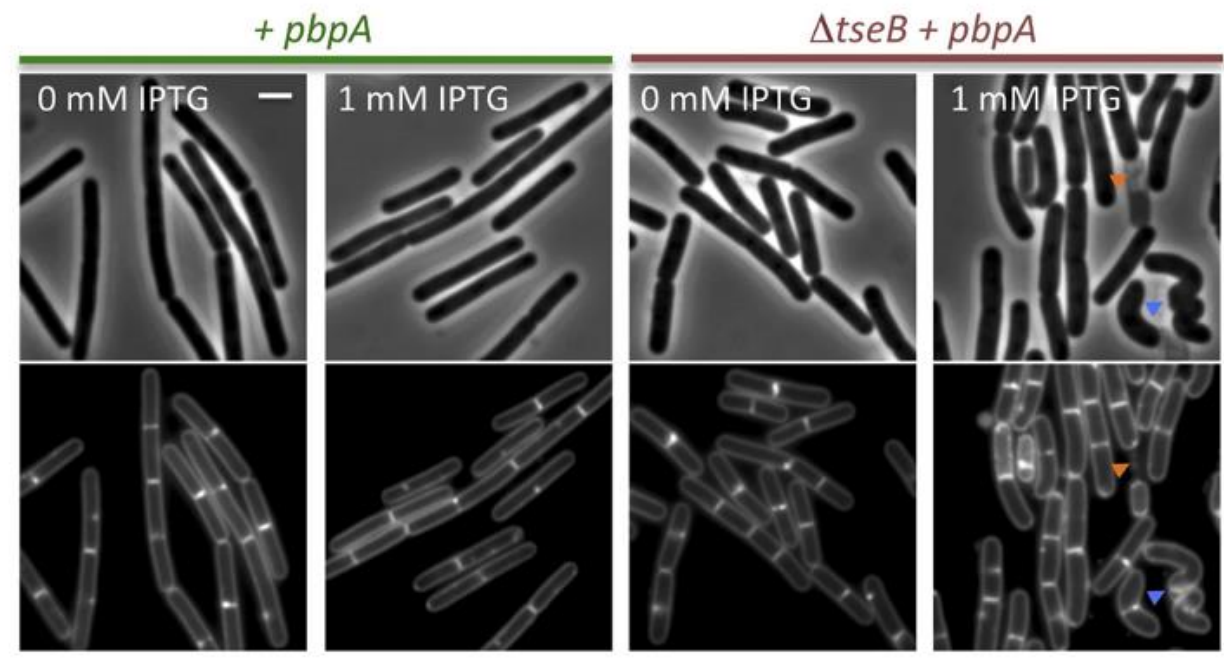

(b)
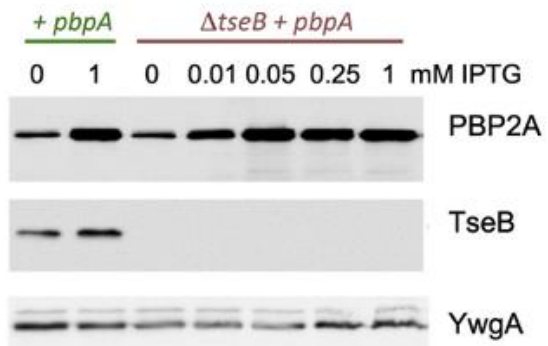

(d)
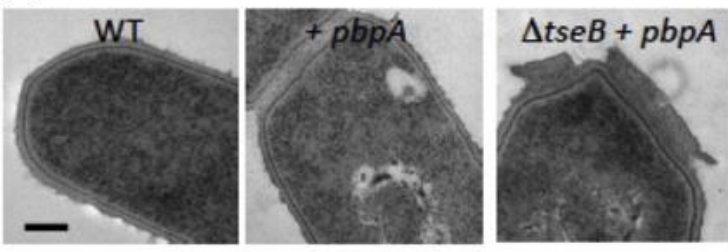

(c)
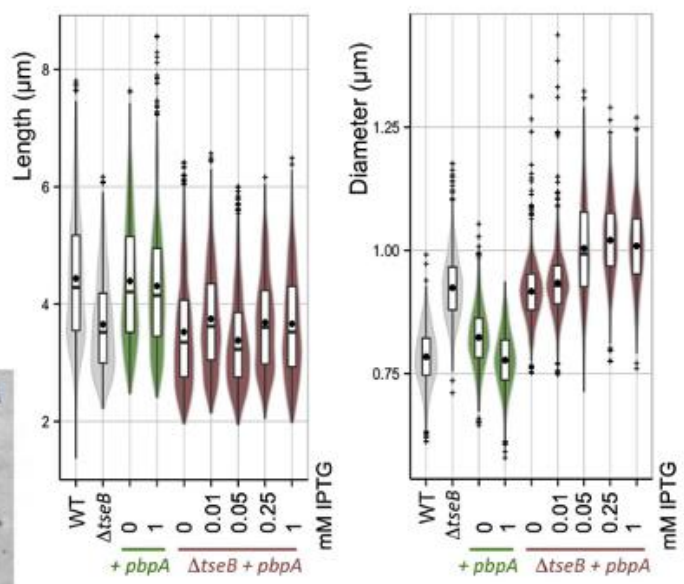

Figure 6: Effect of GFP-PBP2A overproduction in the presence and in the absence of TseB.

The strains analyzed were: a strain harboring an IPTG inducible copy of $p b p A$ in a wildtype background (BTM406) grown in the absence $(+p b p A, 0)$ or in the presence of ITPG $(+p b p A, 1000)$, a strain harboring an IPTG inducible copy of $p b p A$ in a $\Delta t s e B$ mutant background $(\Delta t s e B+p b p A$; BTM426) with increasing amounts of IPTG $(0,10,50,250$, $1000 \mu \mathrm{M})$. All strains were grown in LB to an $\mathrm{OD}_{600} \sim 0.6$.

A- Cell shape was monitored by phase contrast and fluorescence microscopy. Membranes were visualized using the dye FM1-43. Scale bar, $2 \mu \mathrm{m}$.

B- The levels of PBP2A, TseB and YwgA (a protein that we are studying and used as loading control) were monitored by immunoblot of whole cell lysates. 
C- Quantitative analysis of cell length and diameter. Violin plots showing cell length and diameter in the population of the same strains $(n>750)$. All differences mentioned in the text are statistically relevant with Student's t-test $\mathrm{p}$ values below 0.001 .

D- Cell wall structure was assessed by electron microscopy for the wild-type strain, and strains overexpressing $p b p A$ in a wild-type $(+p b p A)$ or $\triangle t s e B$ mutant background $(\triangle t s e B$ $+p b p A)$. A typical cell is shown. Scale bar, $200 \mathrm{~nm}$. 


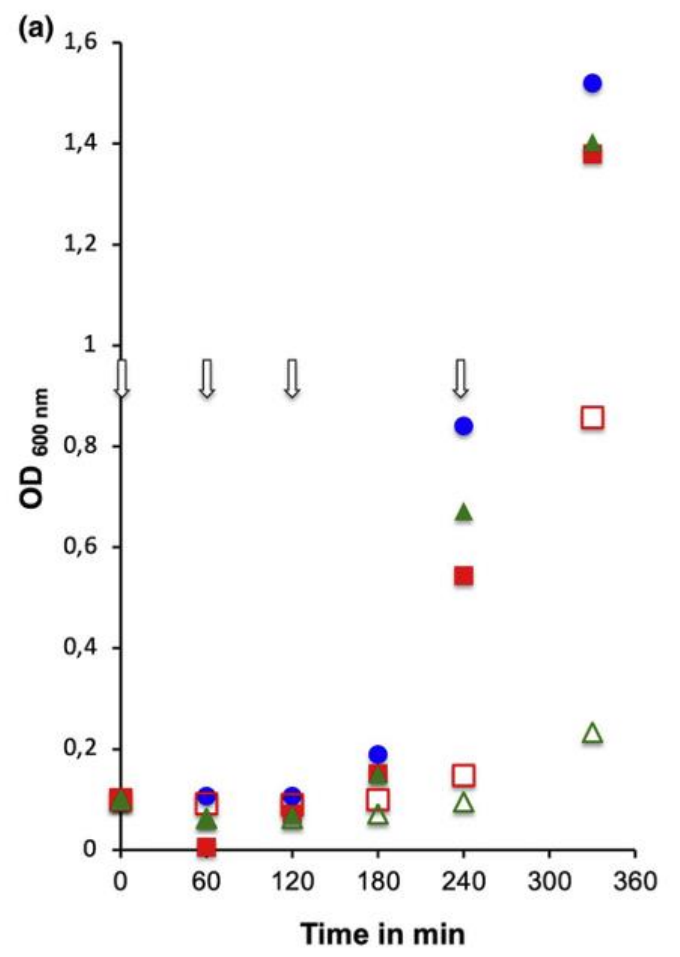

(b)
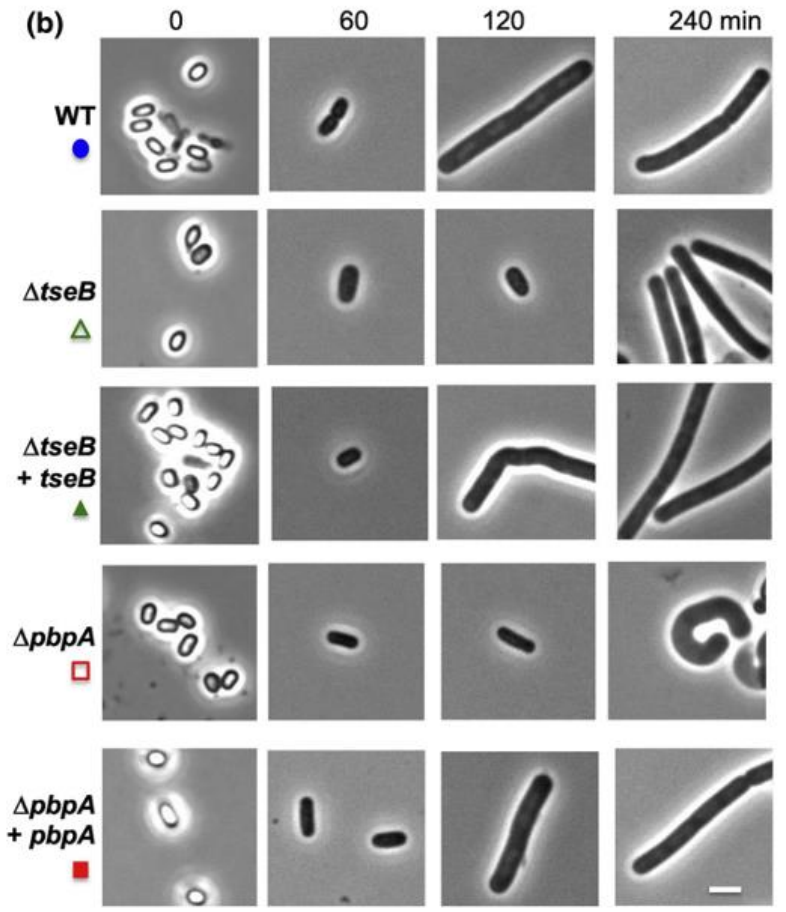

Figure 7: Effect of a deletion of TseB and PBP2A on germination.

A wild-type strain (WT), a $\Delta$ tseB mutant (BJM19), a strain harboring an ectopic IPTG inducible copy of $t s e B$ in a $\triangle t s e B$ mutant background (BJM21), a $\triangle p b p A$ mutant (BTM380), a strain harboring an ectopic IPTG inducible copy of $p b p A$ in a $\triangle p b p A$ mutant background (BJM161) and a strain harboring an ectopic IPTG inducible copy of $p b p A$ in a $\Delta t s e B$ mutant background (BTM 426) were grown during $36 \mathrm{~h}$ in DSM medium. Spore were collected and heated at $80^{\circ} \mathrm{C}$ for $30 \mathrm{~min}$.

A- Spore germination was monitored by measuring the optical density at $600 \mathrm{~nm}$.

B- Analysis of spore and cell morphology by phase contrast microscopy after 0, 60, 120 and 240 min of germination. Scale bar, $2 \mu \mathrm{m}$. 
Table 1: Strains used in this study

\begin{tabular}{|c|c|c|}
\hline Strain name & Genotype & Source \\
\hline Wild-type & Prototrophic wild-type strain, 168CA $\operatorname{trpC}+$ & Nicolas et al., 2012 \\
\hline BJM19 & $\Delta t s e B:: e r m$ & From BGSC \\
\hline BJM21 & $\Delta t s e B:: e r m$, amyE::Phyperspank-tseB (spec) & This work \\
\hline BJM36 & $\Delta t s e B:: e r m, \Delta p b p H$ (markerless) & This work \\
\hline BJM61 & pbpA::pSG5043 (cat Pxyl-gfp-pbpA) & DJ. Scheffers \\
\hline BJM80 & $\begin{array}{l}\Delta t s e B:: e r m \\
\text { pbpA::pSG5043 (cat Pxyl-gfp-pbpA), }\end{array}$ & This work \\
\hline BJM161 & $\begin{array}{l}\Delta p b p A \text { (markerless), } \\
\text { amyE::Phyperspank-pbpA (spec) }\end{array}$ & This work \\
\hline BTM291 & amyE::Phyperspank-tseB-sfgfp (spec) & This work \\
\hline BTM295 & $\begin{array}{l}\Delta t s e B:: e r m \\
\text { amyE::Phyperspank-tseB-sfgfp (spec) }\end{array}$ & This work \\
\hline ВТМ380 & $\Delta p b p A:: e r m$ & From BGSC \\
\hline BTM382 & $\Delta p b p H:: e r m$ & From BGSC \\
\hline BTM402 & $\Delta t s e B:: e r m, \Delta p b p A$ (markerless) & This work \\
\hline BTM406 & amyE::Phyperspank-pbpA (spec) & This work \\
\hline BTM426 & $\begin{array}{l}\Delta \text { tseB::erm, } \\
\text { amyE::Phyperspank-pbpA (spec) }\end{array}$ & This work \\
\hline BTM430 & $\begin{array}{l}\Delta t s e B:: e r m, \\
\text { amyE::Phyperspank-pbpH (spec) }\end{array}$ & This work \\
\hline
\end{tabular}


Table 2: Plasmids used in this study

\begin{tabular}{|c|c|c|}
\hline Plasmid name & Characteristic & Source \\
\hline pDR111 & & $\begin{array}{l}\text { Kind gift of } \\
\text { D. Rudner }\end{array}$ \\
\hline pBM9 & $\begin{array}{l}\text { PCR product encoding YqgP N- } \\
\text { terminal intracellular domain } \\
\text { inserted into pET28a }\end{array}$ & $\begin{array}{l}\text { (Began et al., } \\
\text { 2020) }\end{array}$ \\
\hline $\begin{array}{c}\text { pJM1 } \\
{\left[\text { [GST-PBP2A }^{\mathrm{ECD}}\right]}\end{array}$ & $\begin{array}{l}\text { PCR product encoding C-terminal } \\
\text { extracellular fragment of TseB } \\
\text { inserted into pGEX-4-T1 }\end{array}$ & This work \\
\hline $\begin{array}{c}\text { pJM51 } \\
\left.\text { [His6-PBP2A }{ }^{\mathrm{ECD}}\right]\end{array}$ & $\begin{array}{l}\text { PCR product encoding PBP2A } \\
\text { extracellular domain inserted into } \\
\text { pET28a }\end{array}$ & This work \\
\hline $\begin{array}{c}\text { pJM52 } \\
{[\text { amyE::Phyperspank-tseB ] }}\end{array}$ & $\begin{array}{l}\text { PCR product encoding } \text { TseB } \\
\text { inserted into pDR111 }\end{array}$ & This work \\
\hline $\begin{array}{c}\text { JJM53 } \\
{[\text { amyE:: } \text { Phyperspank-tseB- }} \\
s f G F P]\end{array}$ & $\begin{array}{l}\text { PCR products encoding TseB and } \\
\text { sfGFP inserted into pDR } 111\end{array}$ & This work \\
\hline $\begin{array}{c}\text { pTM52 } \\
{\left[\text { His-TseB }{ }^{\mathrm{ECD}}\right]}\end{array}$ & $\begin{array}{l}\text { PCR product encoding TseB } \\
\text { extracellular domain inserted into } \\
\text { pET28a }\end{array}$ & This work \\
\hline $\begin{array}{c}\text { pTM68 } \\
{\left[\text { amyE::P }{ }_{\text {hyperspank-pbpA ] }}\right.}\end{array}$ & $\begin{array}{l}\text { PCR product encoding PBP2A } \\
\text { inserted into pDR111 }\end{array}$ & This work \\
\hline $\begin{array}{c}\text { pTM69 } \\
{[\text { amyE::Phyperspank-pbpH ] }}\end{array}$ & $\begin{array}{l}\text { PCR product encoding } \mathrm{PBPH} \\
\text { inserted into pDR111 }\end{array}$ & This work \\
\hline $\begin{array}{c}\text { pTM112 } \\
{\left[\text { GST-YjcN }{ }^{E C D}\right]}\end{array}$ & $\begin{array}{l}\text { PCR product encoding C-terminal } \\
\text { extracellular fragment of } \mathrm{YjcN} \\
\text { inserted into pGEX-4-T1 }\end{array}$ & This work \\
\hline
\end{tabular}


Table 3: Oligonucleotide primers used in this study

\begin{tabular}{|c|l|}
\hline Primer & \multicolumn{1}{|c|}{ Sequence* $^{*}$} \\
\hline oJM9 & ccgcgtGGATCCaagcagatcgtgcaaggtga \\
\hline oJM10 & acgatGAATTCcttagttatcagaagacgttgt \\
\hline oJM58 & catgcgGCTAGCttagttatcagaagacgttgtg \\
\hline oJM65 & acaattAAGCTTacataaggaggaactactatgaggagaaataaaccaaaaaag \\
\hline oJM69 & catgcgGCTAGCttatttttactgtgtttttttc \\
\hline oJM81 & gtggtgCTCGAGttagttatcagaagacgttgtg \\
\hline oTM194 & acaattAAGCTTacataaggaggaactactatgagaaaaaagcattaatat \\
\hline oTM195 & atgcgGCTAGCttaaggcgtgatatttttga \\
\hline oTM196 & tttagaCTCGAGaggcgtgatatttttgagaa \\
\hline oTM225 & agccatatgGCTAGCaaatcagccatggcacaaaag \\
\hline oTM226 & ggtggtggtgCTCGAGttaaggcgtgatattttgag \\
\hline oTM375 & ccgcgtGGATCCtttacagcttcttcggaaaaag \\
\hline oTM376 & cacgatGAATTCttacggccctgtgccacaac \\
\hline
\end{tabular}

*Capital letters indicate the recognition sites of restriction enzymes 